\title{
Application and Practice of High-Precision Solar Resource Monitoring Technology in Photovoltaic Power Plant Area
}

\author{
Rong Zhou ${ }^{1}$, Xiaolei Zhang',3 \\ ${ }^{1}$ China Renewable Energy Engineering Institute, Beijing, China \\ ${ }^{2}$ China Institute of Water Resources and Hydropower Research, Beijing, China \\ ${ }^{3}$ Research Center on Flood \& Drought Disaster Reduction of the Ministry of Water Resources, Beijing, China \\ Email: ahuzhxl@163.com, johnsilver@sina.com
}

How to cite this paper: Zhou, R. and Zhang, X.L. (2019) Application and Practice of High-Precision Solar Resource Monitoring Technology in Photovoltaic Power Plant Area. Journal of Power and Energy Engineering, 7, 55-63. https://doi.org/10.4236/jpee.2019.711007

Received: November 1, 2019 Accepted: November 24, 2019 Published: November 27, 2019

\begin{abstract}
Solar resource monitoring and evaluation is the foundation of informatization of photovoltaic power station. In 2016, China began to bring in high-precision solar resource monitoring technology which provides reliable basic data for the photovoltaic informatization development. This paper systematically sorts out design basis, monitoring elements and system architecture of high-precision monitoring station, and analyzes operation effect of high-precision solar resource monitoring station from performance of solar radiation meter and prediction results of luminous power, which provide important data support for analysis of power generation efficiency of photovoltaic module, prediction of power generation of power station, evaluation of operation effect of power station, etc.
\end{abstract}

\section{Keywords}

High-Precision, Solar Resource Monitoring Station, Operation Effect

\section{Introduction}

As a type of renewable clean energy, photovoltaic power generation has been widely concerned by countries all over the world. Photovoltaic industry is of great significance to mitigate global climate change [1] [2]. More and more attention has been paid to solar resource monitoring and evaluation as the foundation of photovoltaic power plant informatization. In 2016 when the first leading photovoltaic power generation base in China was completed [3] [4], high-precision solar resource monitoring station became a part of photovoltaic 
power station construction for the first time, which can effectively realize analysis of power generation efficiency of photovoltaic module, prediction of power generation of power station, operation and maintenance management, performance evaluation and pros and cons analysis.

Compared with traditional solar resource monitoring station, the high-precision solar resource monitoring station has higher requirements for the precision of observation data and the stability of equipment. The equipment shall meet the following requirements: 1) technical requirements of BSRN, WMO standards, ISO 9060 and IEC 60904 international standards, and the requirement of working normally all day [5];2) since most of the solar resource monitoring stations are set in the field, the whole set of equipment and installation technology shall meet the requirement of lightning protection, and requirement of protecting from freezing, strong wind and other extreme weather conditions happened once in 30 years [6];3) the monitoring station shall be equipped with a power supply system due to the unstable field power supply (battery pack with continuous power supply of more than 48 hours).

The national advanced technology photovoltaic demonstration base in Datong mining subsidence area is a construction project aiming to improve energy structure of Shanxi Province, improve ecological environment quality of Datong subsidence area, promote technological progress and industrial development of photovoltaic power generation, and promote economic structure transformation of Datong City. It was built in 2015. The planned installation capacity is 1000 MWp, which is divided into 13 individual projects, including 7 "Top Runner" program projects, with the scale of a single individual project being $100,000 \mathrm{~kW}$; 6 "Top Runner Program + New Technology and New Model Demonstration" projects, with the scale of a single project being 50,000 kW. Taking Datong Top Runner Base as an example, this paper analyzes technical design basis, monitoring elements, system composition and effect evaluation of high-precision solar resource monitoring station, which provides technical support for construction of China's photovoltaic power plant area and analysis of photovoltaic power generation data.

\section{Solar Resource Monitoring Station Technology}

\subsection{Design Basis and Monitoring Elements}

The construction of solar resource monitoring station shall meet requirements in industries like energy, water conservancy, meteorology, environmental protection, big data, etc., which cover more than 10 national standards, industrial technical requirements and policies in solar energy resource assessment, real-time monitoring, resource level and measurement, precipitation monitoring, ground meteorological monitoring, big data application, photovoltaic power station construction, etc., such as Assessment Method for Solar Energy Resources (QX/T 89-2008), Technical Requirements for Solar Energy Resources Real-time Monitoring of Photovoltaic Power Station (GB/T 30153-2013), Specification for 
Precipitation Monitoring (SL 21-2015), Specification for Ground Meteorological Monitoring, Several Opinions of the General Office of the State Council on Using Big Data to Strengthen the Service and Supervision of Market Subjects (GBF [2015] No. 51).

In terms of monitoring elements, according to the Solar Energy Resource Evaluation Method [7] (QX/T89-2008) issued by China Meteorological Administration, at present, the photovoltaic power station monitoring data in China mainly include solar radiation, sunshine, resource stability, environmental elements, etc. (Table 1).

\subsection{Location of Monitoring Station}

Monitoring station shall be located in an area with relatively good solar energy resource, relatively gentle terrain and no major engineering geological problems. The site selection requirements [8] [9] are as follows:

1) Since different photovoltaic power stations are with different array distribution, it is necessary to build a set of solar energy resource monitoring stations in the array of each power station. Fixed stations and tracking stations shall be distributed in the central position of the main array of the power station, or near the average altitude of the array, to ensure that the monitoring data can represent the radiation of the whole power station area.

2) In order to ensure normal and stable operation of the system, the operation of fixed stations need to rely on $220 \mathrm{~V}$ AC power supply as make-up storage battery. The station is required to be located near the box transformer substation due to the voltage drop of long-distance cable laying. When laying cables, it is necessary to avoid crossing of power lines and solar cable lines in the measuring station, and at the same time, prevent cables from passing through the subgrade during construction to reduce impacts on road and ensure safety and reliability of power lines of equipment.

3) The specific installation position of solar radiation sensor shall ensure that there are no or less shelter buildings from east by north $37.5^{\circ}$ to west by north

Table 1. Main monitoring elements of photovoltaic power station in China.

\begin{tabular}{|c|c|c|}
\hline $\mathrm{S} / \mathrm{N}$ & Monitoring elements & Content description \\
\hline 1 & Solar energy resource & $\begin{array}{l}\text { It refers to the cumulative value of total solar radiation on } \\
\text { horizontal plane in a certain period of time, expressed in } \mathrm{MJ} / \mathrm{m}^{2}\end{array}$ \\
\hline 2 & Total solar radiation & Sum of solar direct radiation and diffuse radiation, $\mathrm{MJ} / \mathrm{m}^{2}$ \\
\hline 3 & Sunshine duration & $\begin{array}{l}\text { Duration of each day to reach the radiation value required by } \\
\text { photovoltaic power station }\end{array}$ \\
\hline 4 & Sunshine percentage & Percentage of sunshine duration in duration of possible sunshine \\
\hline 5 & $\begin{array}{l}\text { Stability of solar energy } \\
\text { resource }\end{array}$ & State and range of solar energy resource change in a year \\
\hline 6 & Direct radiation ratio & Ratio of direct radiation to total radiation on horizontal surface \\
\hline 7 & Environmental factors & $\begin{array}{l}\text { Wind speed, wind direction, ambient temperature, humidity, air } \\
\text { pressure, precipitation, etc. }\end{array}$ \\
\hline
\end{tabular}


$37.5^{\circ}$. In principle, the horizontal distance between the shelter building and the observation point shall be more than 10 times of the absolute height difference between the shelter building and the observation point.

\subsection{Solar Resource Monitoring System}

The solar resource monitoring system mainly uses modern communication, automatic control, telemetering, computer and other technologies to collect, transmit, receive and store solar radiation and meteorological information in real time, which provides powerful data support for the evaluation of photovoltaic conversion efficiency of photovoltaic panels, the evaluation of comprehensive benefits of photovoltaic power stations and the evaluation of operation and maintenance of power stations in the photovoltaic “Top Runner" Project. Its role and position are very important.

\subsubsection{System Function}

The system can realize the unattended operation of solar energy resource station, the automatic collection and real-time sending of solar radiation and weather information; real-time receiving of data messages in various types and message decoding, and classified storage of decoded data in database; data upload through the data interface provided by the big platform; remote management of solar energy resource monitoring station; inquiry of data history; inquiry of GIS information; equipment failure, power supply under-voltage and other reminders.

The data monitoring platform is deployed on the server specified by the photovoltaic power generation center in the demonstration base. The data monitoring platform has functions of receiving and processing solar resource data, analyzing and evaluating solar resources, etc.

The data receiving function mainly includes: real-time receiving of data messages in various types from the solar radiation monitoring station of each photovoltaic power station, message decoding, classified storage of data, input in database, data upload via the data interface provided by the big platform, etc.

The data processing function mainly includes: preliminary analysis of data received, data statistics, statement, graphical arrangement and output.

The analysis of solar resources mainly includes: statistical analysis on the total annual solar radiation, analysis on the variation trend of total monthly solar radiation, statistical analysis on the annual sunshine duration of solar energy, analysis on the distribution of mean sunshine duration of solar energy for years, analysis on the stability extent of solar energy, comparative analysis on the cumulative radiation of each station, and comparative analysis on the annual sunshine duration of each station.

The evaluation of solar resources mainly includes: grading evaluation of solar resource richness (the grading evaluation may be carried out in combination with the reference standard for grading of total annual radiation), evaluation of solar energy value in use, evaluation of solar energy stability extent (the evaluation may be carried out in combination with the ratio of minimum value to 
maximum value of the mean radiation of each month in a whole year), evaluation of the optimal use period of the solar energy in one day, and evaluation of photoelectric conversion efficiency of the photovoltaic power station.

\subsubsection{System Composition}

The solar resource monitoring system is mainly composed of two parts: solar energy resource monitoring station and data monitoring platform. Its system architecture is shown as Figure 1. The self-reporting mode is adopted for the working mechanism of the system, which automatically collects, transmits and stores solar radiation and related weather information in intervals of $1 \mathrm{~min}, 5$ $\mathrm{min}, 10 \mathrm{~min}, 60 \mathrm{~min}$ and 1 day. According to the characteristics of solar resource information collection, and in combination with the current situation of the development of communication transmission technologies, the solar resource measurement system adopts GPRS communication mode, which sends the monitored data to the data monitoring center in real time.

\section{Analysis on the Operation Effect of the Solar Resource Monitoring Station}

\subsection{Analysis on the Performance of Solar Radiometer}

The core to evaluate the operation effect of solar resource monitoring station is

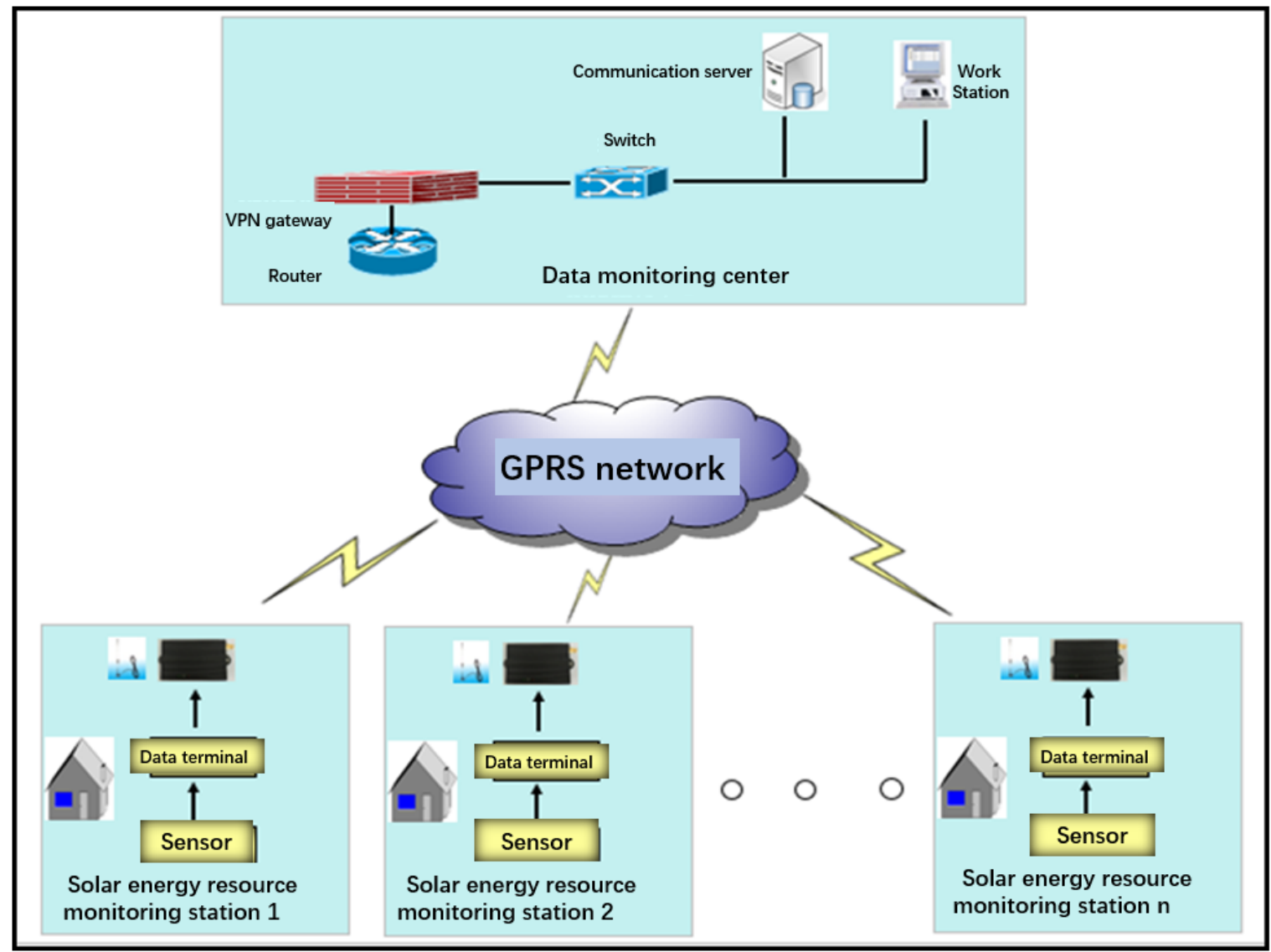

Figure 1. Overall structure of the solar resource monitoring system. 
the analysis on the performance of its sunshine radiometer. Currently, there are mainly 4 mainstream products in and out of China, which are Netherlands Kipp \& Zonen, Japan Eko, US Eppley, and Jinzhou Sunshine Technology of China respectively. Their main performance parameters are shown as Table 2.

From below table, the difference between above 4 types of radiometers is small in the aspect of measurement scope and sensitivity, but is significant in the aspect of precision and response time. Especially, the difference in the performance index of operating temperature range is relatively great.

Taking Datong photovoltaic generation leading base as the example, the outdoor temperature of photovoltaic field area is as low as about $-35^{\circ} \mathrm{C}$ in winter, while in summer, affected by direct sunshine for long hours, actual operating temperature of the radiometer is far higher than $40^{\circ} \mathrm{C}$. In consideration of the effect of operating temperature on the equipment accuracy, the solar resource monitoring stations of the 13 photovoltaic power stations in the base are equipped with 13 CHP1 direct radiometers of Netherlands Kipp \& Zonen (Figure 2), and are installed with SOLYS2 solar trackers (Figure 3), which are suitable for being

Table 2. Comparison of performance parameters of solar radiometers in and out of China.

\begin{tabular}{ccccc}
\hline & $\begin{array}{c}\text { Kipp \& Zonen } \\
\text { (Netherlands) }\end{array}$ & $\begin{array}{c}\text { Eko } \\
\text { (Japan) }\end{array}$ & $\begin{array}{c}\text { Eppley } \\
\text { (the USA) }\end{array}$ & $\begin{array}{c}\text { Jinzhou Sunshine } \\
\text { (China) }\end{array}$ \\
\hline Model & CMP11/CMP10 & MS802/802F & PSP & TBQ-2C \\
Measuring range & $285-2800 \mathrm{~nm}$ & $285-2800 \mathrm{~nm}$ & $0.28 \mu \mathrm{m}-3.0 \mu \mathrm{m}$ & $0.28 \mu \mathrm{m}-3.0 \mu \mathrm{m}$ \\
Sensitivity & $7-14 \mu \mathrm{V} / \mathrm{W} / \mathrm{m}^{2}$ & $\sim 7 \mu \mathrm{V} / \mathrm{W} / \mathrm{m}^{2}$ & $7-14 \mu \mathrm{VW} / \mathrm{m}^{2}$ & $7-14 \mu \mathrm{VW} / \mathrm{m}^{2}$ \\
Daily cumulative precision & $<3.0 \%$ & $<5.0 \%$ & $<6.0 \%$ & $<8.0 \%$ \\
Response time & $<5 \mathrm{~s}$ & $<5 \mathrm{~s}$ & $\leq 30 \mathrm{~s}$ & $\leq 30 \mathrm{~s}$ \\
Operating temperature & $-40^{\circ} \mathrm{C}-80^{\circ} \mathrm{C}$ & $-40^{\circ} \mathrm{C}-80^{\circ} \mathrm{C}$ & $-40^{\circ} \mathrm{C}-80^{\circ} \mathrm{C}$ & $-20^{\circ} \mathrm{C}-40^{\circ} \mathrm{C}$ \\
range & & & &
\end{tabular}

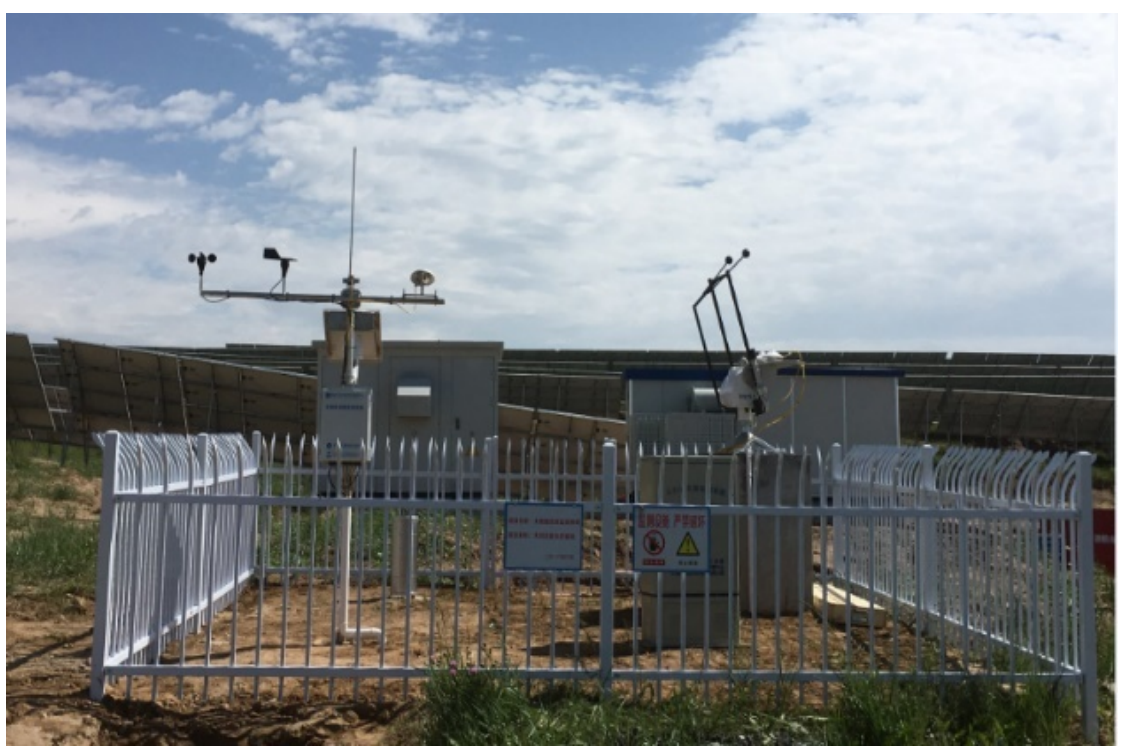

Figure 2. Chart of solar energy resource monitoring stations. 


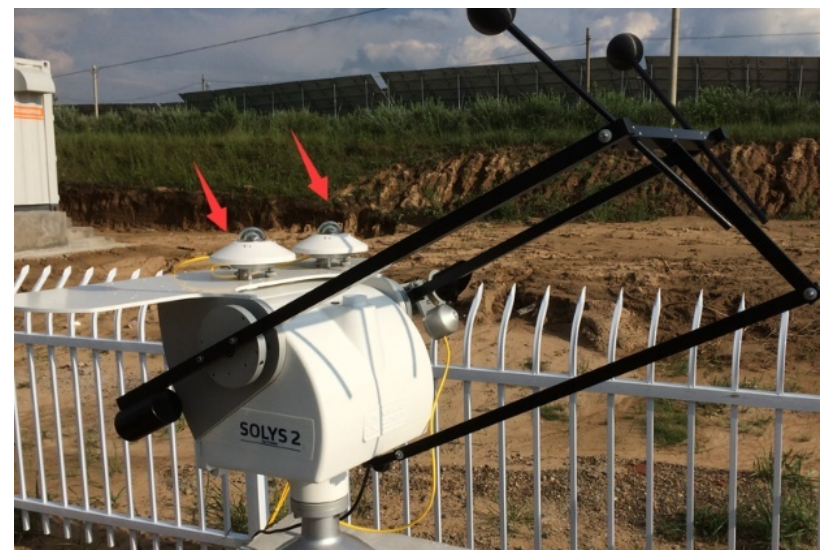

Figure 3. Solar tracker and direct radiometer.

used in unattended field environment with complex weather, have extremely strong low temperature resistance and high wind resisting coefficient, and can be self-heated to prevent it from freezing in Datong's gelid outdoor environment in winter. Meanwhile, for comparative analysis, 1 Jinzhou Sunshine Technology PC-2-T2 photovoltaic power station environment monitoring system is equipped.

Since the base was put into operation in 2016, the equipment of Netherlands Kipp \& Zonen has been operated stably with the operation assurance rate at $100 \%$ and there is no failure to operate due to the equipment itself not being able to adapt to the environment. The equipment's response time in winter is lower than 4 seconds. The equipment from Jinzhou Sunshine Technology is unable to operate normally sometimes under Datong's extremely cold condition in winter.

\subsection{Analysis of Solar Output Power Prediction Result}

As the State Grid has continuously improved the accuracy of photovoltaic output power prediction for the past few years [10], the provincial grid companies have successively formulated the standard for punishment on the solar output power prediction, where the solar output power short-term prediction shall be higher than $85 \%$ and the accuracy rate of ultra-short-term prediction shall be no lower than $90 \%$.

Figure 4 shows the measurement and prediction result of the solar output power of certain power station in Datong. The short-term and ultra-short-term prediction of solar output power was carried out by adopting the time sequence and ant colony analysis algorithm and based on the irradiance and photovoltaic power data history. The measured values and prediction results for 48 hours during September 6-7, 2019 were selected for comparative analysis. The result shows that the accuracy rate of short-term prediction of solar output power is $86.5 \%$, while the accuracy rate of ultra-short-term prediction of solar output power is $91 \%$. It is indicated that the prediction of solar output power by the data from high-accuracy monitoring station corresponds to the actual power generation trend. 

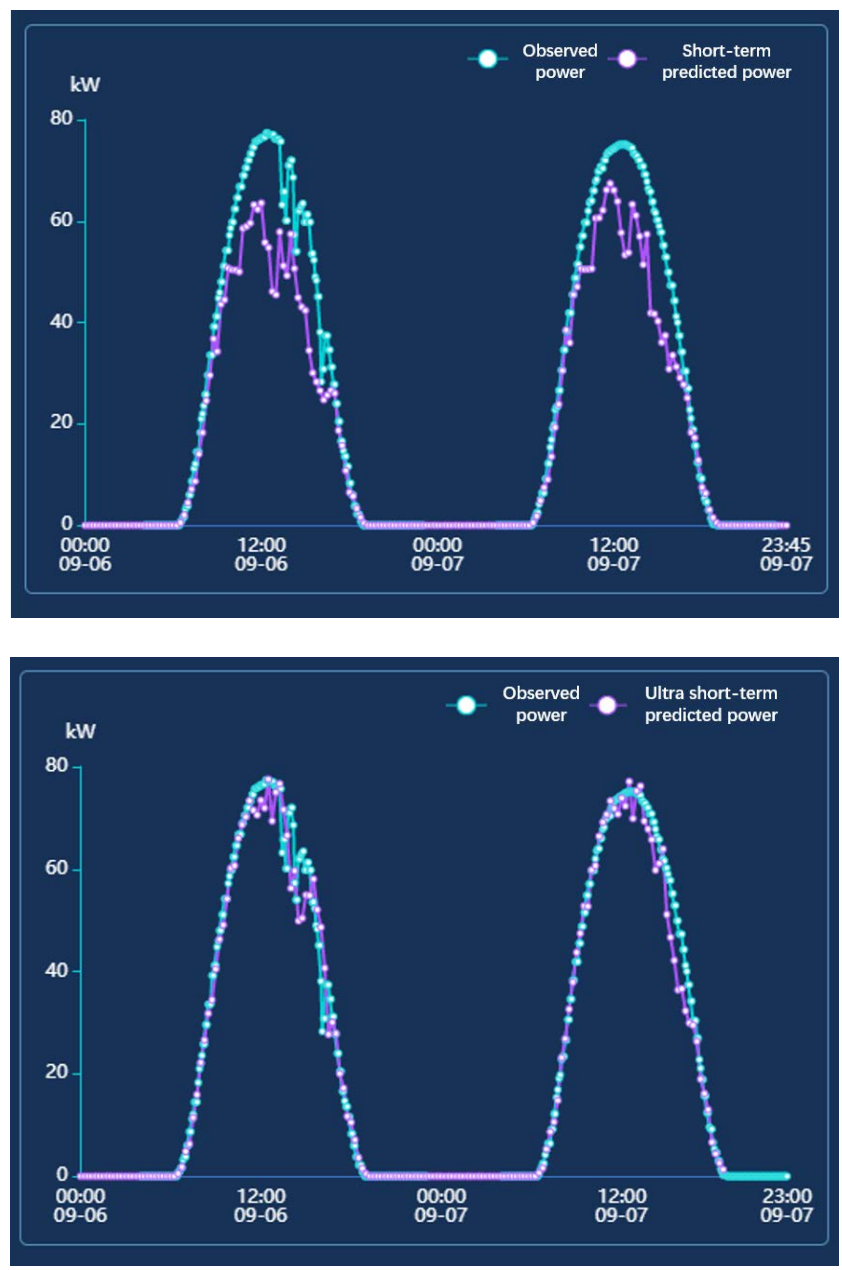

Figure 4. Observed and predicted power of short-term and ultra-short-term measurement results.

\section{Conclusions}

Taking Datong leading base as the example, by sorting the high-precision solar resource monitoring station technologies systematically, and evaluating the operation effect of solar resource monitoring station, the author drew the following conclusions:

1) As an important component of PV power station, the high-precision solar resource monitoring station plays a prominent role in analyzing the generation efficiency of photovoltaic modules, predicting the generating capacity of power station, evaluating the operation effect of power station, etc.

2) The solar resource monitoring station has high requirement on the precision of observation data and the stability of equipment. The equipment is required to meet multiple industry requirements such as energy, water conservancy, weather, environmental protection, big data, etc. Moreover, high performance of a sunshine radiometer is required.

3) Solar resource monitoring data based on precision is the foundation to evaluate the incident photon-to-electron conversion efficiency of PV power sta- 
tion and the accuracy of solar output power accuracy, and the power generation indicator data of PV power station so obtained is more convincing. Accurate solar resource monitoring data is helpful for PV power station investing and operating enterprises to carry out standard-reaching prediction.

\section{Acknowledgements}

This paper was supported by the Project of Construction of public information service platform of national advanced technology demonstration base in Datong coal mining subsidence area (Project No. ZY-KYKT-20170189).

\section{Conflicts of Interest}

The authors declare no conflicts of interest regarding the publication of this paper.

\section{References}

[1] Zhang, J.Y., Li, D., Yang, P., et al. (2014) Development Trend Analysis of Photovoltaic Power Generation. Renewable Energy, 32, 127-132.

[2] State Council of the People's Republic of China (2006) Outline of the National Plan for Medium and Long-Term Scientific and Technological Development (2006-2020).

[3] National Development and Reform Commission, PRC (2007) Medium and Long-Term Development Plan for Renewable Energy.

[4] Feng, W.W. (2016) The Country's First PV Leader Program Is Going Full Speed Ahead. Energy Saving and Environmental Protection, 6, 42-44.

[5] Wang, B.Z. and Sheng, Y.B. (2014) The World Meteorological Organization's New Classification Standards for Radiation Observation Stations. The Solar Energy, 11, 6-8.

[6] Li, Y.Z. and Li, Z. (2016) Comparison and Selection of Solar Radiation Data of Photovoltaic Power Generation Projects. Architecture Electric, 35, 35-40.

[7] Shen, Y.B. (2017) Research Progress of Solar Energy Resource Assessment Methods in China. Advances in Meteorological Technology, 1, 77-84.

[8] Luo, J.Y. and Liao, D.J. (2016) Location of Distributed Photovoltaic Power Station. China Science and Technology Information, 11, 34-36.

[9] Ma, M., Wang, N.B. and Ma, Y.H. (2017) Analysis and Research on Layout Optimization of Monitoring Network of Photovoltaic Power Station Based on Wireless Sensor Technology. China Science and Technology Achievements, 8, 43-46.

[10] Gong, Y.F., Lu, Z.X., Qiao, Y., et al. (2016) Photovoltaic Power Prediction Technology. Automation of Power System, 40, 146-157. 